\title{
Brachytherapy in Lung Cancer: Review and Case Report
}

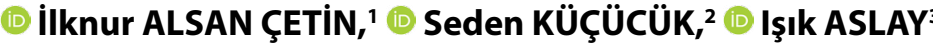 \\ 'Department of Radiation Oncology, Marmara University, İstanbul-Turkey \\ ${ }^{2}$ Department of Radiation Oncology, İstanbul University, İstanbul-Turkey \\ ${ }^{3}$ Department of Radiation Oncology, Acıbadem Hospital, İstanbul-Turkey
}

\begin{abstract}
SUMMARY
Metastatic non-small cell lung cancer remains the leading cause of cancer death worldwide. Endobronchial brachytherapy for the treatment of lung cancer may be used alone, in combination with surgery, or with external-beam radiation. The intent of treatment may be cure or palliation of symptoms. The patient was 59-year-old male who applied to Istanbul University Oncology Institute Radiation Oncology Department. Pathologically was diagnosed as squamous cell carcinoma in 2006. Neoadjuvant chemoradiotherapy was performed prior to diagnosis of stage IIB. A 34x28mm mass was found in the right lungs at 2012. Since the patient complained for cough and hemoptysis, EBBRT was applied with 2x5 Gy HDR in 2012. After the treatment, palliation was achieved in the patient's symptoms.
\end{abstract}

Keywords: Brachytherapy; lung cancer.

Copyright $\odot$ 2019, Turkish Society for Radiation Oncology

\section{Introduction}

Lung cancer is one of the most common fatal malignancies in men. In women, it is the second most common cause of death from cancer.[1] Since the 1920s, pulmonary brachytherapy (BRT) using radon capsules and a rigid bronchoscope started being employed. Nowadays, the most commonly utilized Ir-192 is used for HDR-endobronchial (EB)-BRT and I-125 is used for interstitial (ISI)-BRT. Ir-192 is contained in steel capsules and has a half-life of 74 days. I- 125 is contained in titanium capsules and has a half-life of 59 days. EBBRT can be used in curative [2,3], palliative, postoperative residual or relapse, recurrence after radiotherapy (RT), boost after curative $\mathrm{RT}$, occult lung tumors $[3,4]$, and endobronchial metastases. It is also useful in small tumors that cannot tolerate surgery or RT. Approximately half of the lung tumors may lead to periodic distress due to symptoms. $[5,6]$ EB-BRT provides palliation at a rate of 54\%-100\% in the treatment of these symptoms. Application varies according to tumor structure, location, and degree of obstruction. Catheter placement should be performed in the bronchoscopy room. Usually 1-2 catheters are sufficient, but more catheters may be needed rarely. There is no consensus on the most appropriate fraction. The recommended dose for palliation is $3 \times 7.5 \mathrm{~Gy}, 2 \times 10 \mathrm{~Gy}$ or $4 \times 6 \mathrm{~Gy}$ to be applied to $1 \mathrm{~cm}$ beyond. For patients who have received radiotherapy before, it can be applied as $2 \times 7.5 \mathrm{~Gy}, 3 \times 5$ Gy or $4 \times 4$ Gy. The recommended dose for primary application is $5-47 \mathrm{~Gy}(1-5 \mathrm{frx})$.

Implementation of EB-BRT is contraindicated in patients who cannot tolerate bronchoscopy, need urgent airway opening and have a risk of fistulization, increased risk of bleeding or external bronchial compression. It is also contraindicated when the catheter cannot reach the tumor. While placing the catheter during bronchoscopy, pneumothorax, bronchospasm, hemoptysis, pneumonia, cardiac arrhythmia, or hypotension can be observed.

After EB-BRT, acute radiation bronchitis, stenosis, esophagitis, or fatal hemoptysis may be observed in the early or late period. $[7,8]$ The incidence of fatal hemop- 
tysis is $8 \%$. The incidence of fatal hemoptysis is $8 \%$, median time is 5 months. Progression of the disease or higher number of adjacent vessel dose per fraction, more than one endobronchial brachytherapy (EBBRT) implementation, high-dose ERT, and application of wide area ERT may cause fatal hemoptysis.

\section{Case}

A 59-year-old male was referred for palliative radiotherapy to Istanbul University Oncology Institute Radiation Oncology Department. In 2006, pathological diagnosis was squamous cell carcinoma. Neoadjuvant chemoradiotherapy was performed prior to diagnosis of stage IIB. Radiotherapy was applied to the right lung and mediastinum (30 Gy/15 frx). In 2012, bronchoscopy revealed a mass on the right lateral wall distal to the trachea. Mass excision was performed. On performing computer tomography after 7 months, a 34 $\mathrm{mm} \times 28 \mathrm{~mm}$ mass in the right lung was detected. Since the patient complained of cough and hemoptysis, EBBRT was applied at $2 \times 5$ Gy HDR in 2012. After treatment, palliation was achieved (Fig. 1).

\section{Discussion}

There are numerous prospective and retrospective studies on EB-BRT.[9] In a prospective randomized study by Huber et al., 99 patients were randomized into two groups; in the first group 60 Gy ERT was administered, while in the second group HDR-BRT (4.8 Gy) was administered as an additional dose before and after ERT. Median survival was significant in patients with squamous cell carcinoma in group $2(\mathrm{p}=0.09)$, and local control was significantly higher.[10]

In a prospective randomized study conducted by Langendijk and colleagues, 95 patients with non-small cell lung cancer (NSCLC) were included. Group 1 was treated with $2 \times 7.5$ Gy EB-BRT (1-8 days) and $30 \mathrm{~Gy}$ ERT (2-30 days). Group 2 was treated with 60 Gy ERT. In Group 1, ERT was more beneficial, especially for tumors with occlusion in the main bronchus. Improvement of pneumothorax status due to tumor and recovery of dyspnea were observed.[11]

Ozkok and colleagues have retrospectively evaluated 158 patients with EB-BRT. Group 1 comprised of 43 patients with stage III NSCLC, who were treated with 60 Gy ERT and $3 \times 5$ Gy HDR-EB-BRT for palliation, Group 2 comprised of 74 patients, who were treated with 30 Gy ERT and $2 \times 7.5$ Gy HDR-EB-BRT for palliation and Group 3 comprised of 41 patients with recurrent disease who were treated with $3 \times 7.5 \mathrm{~Gy}$ HDR-EB-BRT for palliation. Fatal hemoptysis rate was $11 \%$. As prognostic factors, treatment aim, total BED,

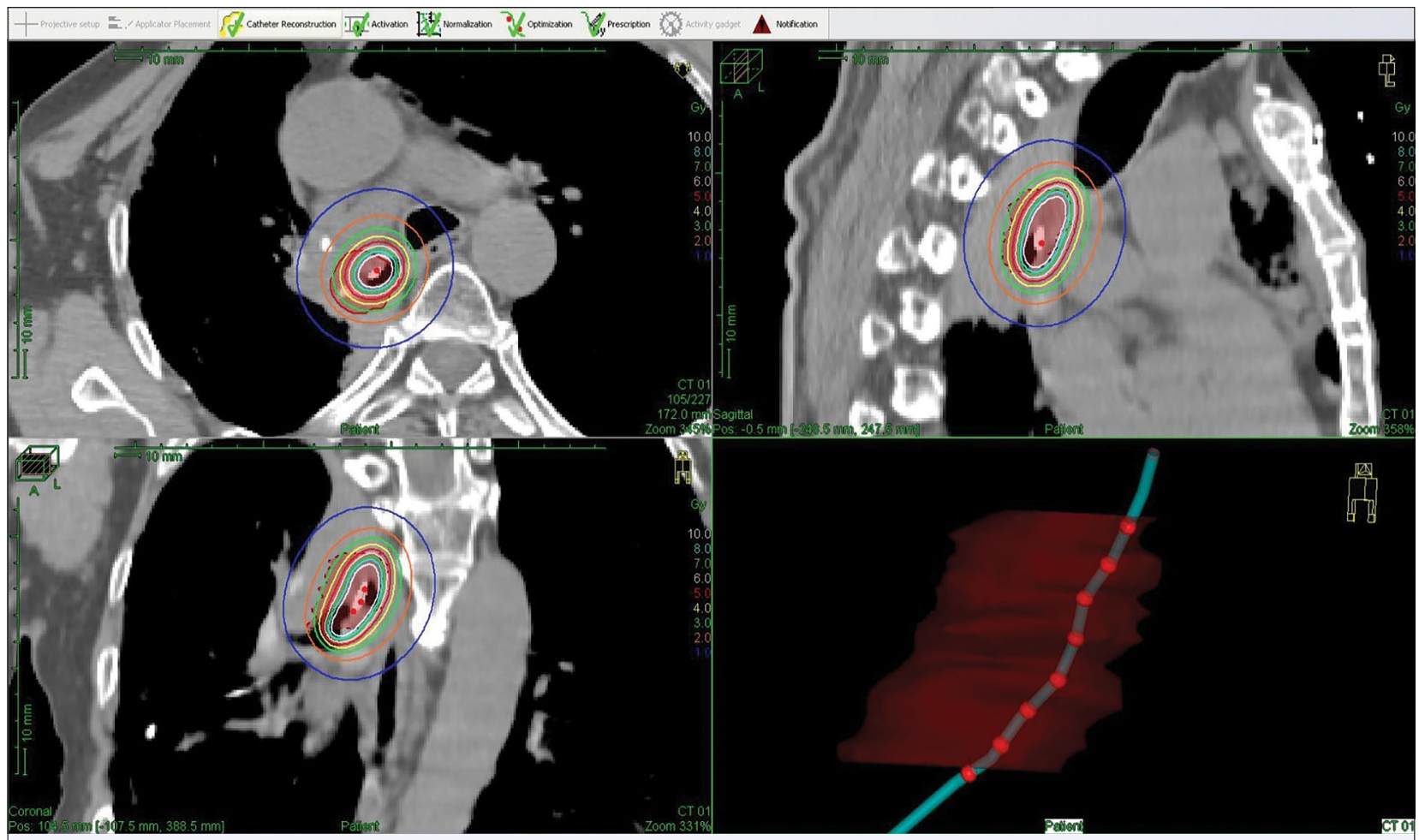

Fig. 1. Isodose distribution of patient treatment. 
and fraction number were found to be statistically significant.[12]

ISI-BRT is an effective method. It can be used in cases with residual or surgical margins in intraoperative use. Inoperable cases can be implanted with temporary or permanent seeds or catheters.[13-17] It is possible to increase local control with high-dose applications.[18]

In conclusion, EB-BRT and ISI-BRT are effective methods in appropriate patients. For both methods, experienced personnel are needed in our country.

Peer-review: Externally peer-reviewed.

Conflict of Interest: The authors have no of interest.

Financial Support: None declared.

\section{References}

1. Stewart BW, Wild CP. World cancer report 2014. International Agency for Research on cancer. Available at: https://www.drugsandalcohol.ie/28525/1/World\%20 Cancer\%20Report.pdf. Accessed February 15, 2019.

2. Rochet N, Hauswald H, Stoiber EM, Hensley FW, Becker HD, Debus J, et al. Primary radiotherapy with endobronchial high-dose-rate brachytherapy boost for inoperable lung cancer: long-term results. Tumori 2013;99(2):183-90.

3. Kawamura H, Ebara T, Katoh H, Tamaki T, Ishikawa $\mathrm{H}$, Sakurai $\mathrm{H}$, et al. Long-term results of curative intraluminal high dose rate brachytherapy for endobronchial carcinoma. Radiat Oncol 2012;7:2-6.

4. Saito M, Yokoyama A, Kurita Y, Uematsu T, Tsukada $\mathrm{H}$, Yamanoi T. Treatment of roentgenographically occult endobronchial carcinoma with external beam radiotherapy and intraluminal low-dose-rate brachytherapy: second report. Int J Radiat Oncol Biol Phys 2000;47(3):673-80.

5. Skowronek J, Kubaszewska M, Kanikowski M, Kanikowski M, Chichel A, Mlynarczyk W. HDR endobronchial brachytherapy (HDRBT) in the management of advanced lung cancer-comparison of two different dose schedules. Radiother Oncol 2009;93(3):436-40.

6. de Aquino Gorayeb MM, Gregorio MG, de Oliveira EQ, Aisen S, Carvalho $\mathrm{H}$ de A. High-dose-rate brachytherapy in symptom palliation due to malignant endobronchial obstruction: a quantitative assessment. Brachytherapy 2013;12(5):471-8.

7. Murakami N, Kobayashi K, Nakamura S, Wakita A, Okamoto $\mathrm{H}$, Tsuchida $\mathrm{K}$, et al. A total EQD2 greater than 85 Gy for trachea and main bronchus D2cc being associated with severe late complications after definitive endobronchial brachytherapy. J Contemp Brachytherapy 2015;7(5):363-8.

8. Lee SJ, Lee JY, Jung SH, Lee SH, Lee JH, Kim CW, et al. A case of radiation bronchitis induced massive hemoptysis after high-dose-rate endobronchial brachytherapy. Tuberc Respir Dis (Seoul) 2012;73(6):325-30.

9. Nguyen NTA, Sur RK. Brachytherapy in lung cancer: a review. Transl Cancer Res 2015;4(4):381-96.

10. Huber RM, Fischer R, Hautmann H, Pöllinger B, Häussinger K, Wendt T. Does additional brachytherapy improve the effect of external irradiation? A prospective, randomized study in central lung tumors. Int J Radiat Oncol Biol Phys 1997;38(3):533-40.

11. Langendijk $\mathrm{H}$, de Jong J, Tjwa $\mathrm{M}$, Muller $\mathrm{M}$, ten Velde G, Aaronson N, et al. External irradiation versus external irradiation plus endobronchial brachytherapy in inoperable non-small cell lung cancer: a prospective randomized study. Radiother Oncol 2001;58(3):257-68.

12. Ozkok S, Karakoyun-Celik O, Goksel T, Mogulkoc N, Yalman D, Gok G, et al. High dose rate endobronchial brachytherapy in the management of lung cancer: response and toxicity evaluation in 158 patients. Lung cancer 2008;62(3);326-33.

13. Hilaris BS, Martini N. Interstitial brachytherapy in cancer of the lung: 20 year experience. Int $\mathrm{J}$ Radiat Oncol Biol Phys 1979;5(11-12):1951-6.

14. Hilaris BS, Martini N. Current state of intraoperative interstitial brachytherapy in lung cancer. Int J Radiat Oncol Biol Phys 1988;15(6):1347-54.

15. Nag S, Rekha G, Tai DL, Pate J. Interstitial radiation implantation for unresectable non-oat-cell carcinoma of the lung. Techniques and preliminary results. Am Surg 1985;51(8):482-6.

16. Mutyala S, Stewart A, Khan AJ, Cormack RA, O'Farrel D, Sugarbaker D, et al. Permanent İodine-125 interstitial planar seed brachytherapy for close or positive margins for thoracic malignancies. Int J Radiat Oncol Biol Phys 2010;76(4):1114-20.

17. Ricke J, Wust P, Wieners G, Hengst S, Pech M, Lopez Hanninen E, et al. CT-guided interstitial single-fraction brachytherapy of lung tumors: phase I results of a novel technique. Chest 2005;127(6):2237-42.

18. Stewart AJ, Mutyala S, Holloway CL, Colson YL, Devlin PM. Intraoperative seed placement for thoracic malignancy-A review of technique, indications, and published literature. Brachytherapy 2009;8(1):63-9. 